\title{
The Influence Mechanism of Performance Assessment Orientation on Knowledge Hiding
}

\author{
Yiran Liu* and Wenbing Wu
}

\author{
School of Economics and Management, Beijing Jiaotong University, Beijing, China \\ ${ }^{*}$ Corresponding author. Email:714868283@qq.com
}

\begin{abstract}
Drawing on social exchange theory and social information processing theory, the paper analyzes the impact of performance appraisal orientation on knowledge hiding behavior and further discusses the mediating role of competitive climate and cooperative climate. By a questionnaire survey to knowledge employees in Hebei, Beijing and Tianjin, we collected 229 samples. The hierarchical regression model is used to explore the influencing mechanism of knowledge hiding. The results verify all hypotheses as well as shed light on the practice of management.
\end{abstract}

Keywords: Knowledge hiding, Evaluative performance appraisal, Developmental performance appraisal, Cooperative climate, Competitive climate.

\section{INTRODUCTION}

The complexity of today's work continues to increase. In order to gain more competitive advantages, organizations have greatly increased their emphasis on knowledge management. As the carrier of knowledge transfer and application, employees face higher expectations of sharing knowledge with colleagues. However, although many companies have invested heavily in systems and practices that promote knowledge transfer between employees, in fact, employees not only break away from knowledge sharing, but also actively and intentionally hide knowledge from colleagues [1]. Therefore, how to effectively prevent knowledge hiding to realize the sharing and transmission of organizational knowledge has become an urgent problem that needs to be solved in the current knowledge management field.

However, although the similarities between knowledge hiding and knowledge sharing, the motives of them are completely different [2]. Therefore, the mechanism of knowledge hiding cannot be measured by the existing research results of knowledge sharing. Throughout the previous research on knowledge hiding, knowledge characteristics, the relationship between seeker and concealer, individual characteristics, and organizational environment are important antecedents of knowledge hiding [3]. Performance appraisal (PA) is a very important strategy in the process of organizational management, which can guide the cooperative behavior or extra role behavior of employees. Therefore, the antecedent variable of PA orientation can be introduced to investigate its influence mechanism on individual knowledge hiding behavior. Besides, in the previous research on the mechanism of knowledge hiding, although some scholars involved in the moderating role of organizational climate on knowledge hiding, they did not discuss it from the two dimensions of competitive climate and cooperative climate.

\section{THEORY AND HYPOTHESIS}

\subsection{Performance Appraisal Orientation and Knowledge Hiding}

According to the dual purpose of performance appraisal, performance appraisal can be divided into evaluation orientation and development orientation [4]. Evaluative PA focuses on comparing the past performance of employees to a set standard or other organizational members [5], which can be used to make personnel decisions within the organization. Developmental PA is concerned with the future of employees and the cultivation of potential. Through regular performance feedback, managers can find ways to stimulate employees' potential and improve work performance, as well as employees find their own problems and future direction [4]. 


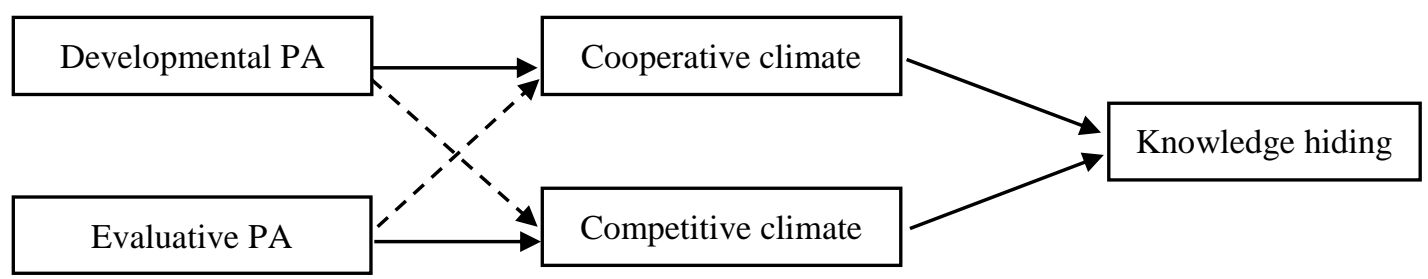

Figure 1 Theoretical model.

Knowledge hiding refers to the behavior of individuals deliberately concealing or refusing to give the knowledge requested by others in a certain attempt [5]. Knowledge hiding consists of three possible behaviors: rationalized hiding, evasive hiding and playing dumb. Rationalized hiding does not necessarily involve deception, which means that the concealer explains his own knowledge hiding behavior by implying that the other party cannot provide the requested knowledge or disagreeing with the third party. Evasive hiding involves deception, which means that the concealer provides inaccurate information, or delays helping and has no intention to really help. Playing dumb is also deceptive, which means that the concealer pretends that he does not understand the question and is not willing to help [6].

Social Exchange Theory believes that people generally have feedback psychology and behaviors when they are positively treated. Applying this theory, employees will actively give back to the organization they care about [7]. Therefore, when employees perceive that the organization's performance appraisal has given themselves incentives, they often take the initiative to complete non-task performance to give back to the organization's concern. This way, they are more inclined to share knowledge with colleagues. On the contrary, employees in organizations that implement evaluative PA may feel higher pressure and are unwilling to make behaviors that are beneficial to others. Thus, they reduce the will and behavior of sharing, that is, people will produce know-ledge hiding. Thus, this article makes the following assumptions:

H1: Developmental PA has a significant negative effect on knowledge hiding.

$\mathrm{H} 2$ : Evaluative PA has a significant positive effect on knowledge hiding.

\subsection{Performance Appraisal Orientation and Organizational Climate}

Competitive atmosphere is a concept based on competitiveness. Brown et al. defined competitive atmosphere as employees' perception of organizational rewards depends on the comparison with others' performance [8]. Competitive atmosphere includes two aspects: compet-itive psychological atmosphere (personal opinion) and competitive team atmosphere (view shared by team members). A cooperative atmosphere is a team atmosphere that emphasizes the interdependence of members to achieve goals and achieves achievements through unity, which can improve team information sharing and increase productivity [9]. In terms of efficiency, a co-operative atmosphere can benefit the group. However, high performing employees receive less support, because the positive deviation of high-performing employees will make other colleagues feel lack of unity, so they will pass Reduce support to moderate group commonality [10].

Since the purpose of developmental performance appraisal is to tap the long-term development potential of employees, employees are more likely to feel an open and inclusive organizational culture, and the internal organization will also attach importance to communication between employees, thereby forming a good atmosphere of unity and cooperation. On the contrary, the results of appraisal performance appraisal are directly linked to personal economic growth. Under pressure perception, each member of the organization will pay more attention to cultivating their own unique competitiveness, that is, forming a strong competitive psychological atmosphere [11]. To get a salary increase and promotion. In this way, the integrity of the organization will be weakened, the independence of individuals will be highlighted, promote a competitive team atmosphere, and ultimately create a competitive atmosphere. Therefore, we propose the following assumptions:

H3: Developmental PA is positively related to cooperative climate.

H4: Evaluative PA is positively related to competitive climate.

\subsection{The Mediating Role of Organizational Climate}

So, how does the organizational climate play an intermediary role between performance appraisal orientation and knowledge hiding behavior? The theory of social information processing insists that individuals will compare perceived information with existing knowledge and experience to interpret clues to determine their own attitudes and behaviors by evaluating information [12], that is, individuals' 
attitudes and behaviors are affected by the organization. The organizational climate can be regarded as the information provided by the organizational environment, which will affect the attitude and behavior of employees. Accordingly, the mediating effect of the organizational climate may play a role in two steps. First, employees will explain the organization's PA orientation and judge the organizational atmosphere built by this appraisal method. Second, according to the perceived nature of the organizational climate, employees will respond in different ways.

If employees feel that they are in a cooperative atmosphere, success requires cooperation [13], so employees are unlikely to hide knowledge. Since developmental performance appraisal can help employees improve their behavior and performance, it is an organization's investment in employees. Therefore, in a cooperative atmosphere, employees may tend to reduce knowledge hiding to promote self-improvement. The essence of appraisal is that there is a strictly calculated economic relationship between the organization and its employees [5], creating a threatening competitive atmosphere. The message of this atmosphere is to require employees to focus on improving their own performance and not to be too concerned about other activities or behaviors of the organization [10]. Therefore, employees are reluctant to provide behaviors outside their roles [14], which reduces interaction and communication with colleagues and increases knowledge hiding [15]. Based on the above analysis, this article assumes:

H5: Cooperative climate plays an intermediary role between developmental PA and knowledge hiding.

H6: Competitive climate plays an intermediary role between evaluative PA and knowledge hiding.

Table 1. Scale reliability and validity analysis

\begin{tabular}{|c|c|c|c|c|c|}
\hline Variables & Items & Factor loadings & Cronbach's $\alpha$ & $C R$ & AVE \\
\hline \multirow{5}{*}{ Developmental PA } & DP1 & 0.860 & \multirow{5}{*}{0.886} & \multirow{5}{*}{0.912} & \multirow{5}{*}{0.690} \\
\hline & DP2 & 0.774 & & & \\
\hline & DP3 & 0.830 & & & \\
\hline & DP4 & 0.872 & & & \\
\hline & DP5 & 0.815 & & & \\
\hline \multirow{4}{*}{ Evaluative PA } & EP1 & 0.794 & \multirow{4}{*}{0.766} & \multirow{4}{*}{0.852} & \multirow{4}{*}{0.591} \\
\hline & EP2 & 0.781 & & & \\
\hline & EP3 & 0.760 & & & \\
\hline & EP4 & 0.738 & & & \\
\hline \multirow{5}{*}{ Cooperative Climate } & cooc1 & 0.649 & \multirow{5}{*}{0.794} & \multirow{5}{*}{0.839} & \multirow{5}{*}{0.569} \\
\hline & coOc2 & 0.699 & & & \\
\hline & coOc3 & 0.893 & & & \\
\hline & COOC4 & 0.753 & & & \\
\hline & COOC5 & 0.728 & & & \\
\hline \multirow{4}{*}{ Competitive Climate } & COMC1 & 0.844 & \multirow{4}{*}{0.787} & \multirow{4}{*}{0.861} & \multirow{4}{*}{0.614} \\
\hline & COMC2 & 0.831 & & & \\
\hline & COMC3 & 0.561 & & & \\
\hline & COMC4 & 0.859 & & & \\
\hline \multirow{12}{*}{ Knowledge Hiding } & $\mathrm{RH} 1$ & 0.825 & \multirow{12}{*}{0.873} & \multirow{12}{*}{0.962} & \multirow{12}{*}{0.699} \\
\hline & $\mathrm{RH} 2$ & 0.821 & & & \\
\hline & $\mathrm{RH} 3$ & 0.878 & & & \\
\hline & $\mathrm{RH} 4$ & 0.896 & & & \\
\hline & EH1 & 0.816 & & & \\
\hline & $\mathrm{EH} 2$ & 0.865 & & & \\
\hline & $\mathrm{EH} 3$ & 0.856 & & & \\
\hline & EH4 & 0.777 & & & \\
\hline & PD1 & 0.760 & & & \\
\hline & PD2 & 0.852 & & & \\
\hline & PD3 & 0.847 & & & \\
\hline & PD4 & 0.617 & & & \\
\hline
\end{tabular}




\section{METHOD}

\subsection{Measures}

Five-point Likert-type scales ranging from 1 ("strongly disagree") to 5 ("strongly agree") were used in this study. We measured PA orientation with nine items from Boswell and Boudreau (2000). Five items by Flynn and Chatman (2001) were adapated to measure co-operative climate and four items by Brown et al. (1998) were adapted to measure competitive climate. Know-ledge hiding was assessed with a 12-item scale developed by Connelly et al. (2012). All variables are measured with employee self-reporting and adjusted according to the Chinese context to ensure the accuracy of the measurement. To account for the possible influence of demographic variables on the research results, we controlled for age, gender, education, company type, rank and work experience of the employees.

\subsection{Samples}

We conducted a questionnaire survey of knowledge workers in Beijing, Tianjin and Hebei. A total of 300 questionnaires were distributed. Invalid questionnaires were filtered through polygraph questions and questionnaires with identical and logically contradictory answers were eliminated. Finally, 229 valid questionnaires were collected, with an effective recovery rate of $76.33 \%$. The participants work in different type of companies, about $67 \%$ of them were female and $44.1 \%$ were between the age of 21 and $30.70 .3 \%$ of respondents reported under 10 years of work experience and $63.8 \%$ reported as general staff.

\section{RESULTS}

\subsection{Reliability and Validity Analysis}

Considering that the data may have common method deviations, Harman's single factor analysis method is used to analyze the problems of the scale. The results show that a total of 6 factors are obtained without rotation, the maximum principal component is $26.015 \%$, and the explained variation is less than $40 \%$, which shows that there is no serious common method deviation in this study.

Secondly, the Cronbach $\alpha$ coefficients of all variables are greater than 0.7 , indicating that the overall scale has good reliability. Next, we examined the KMO value and the Bartlett sphere shape test. The KMO value is greater than 0.50, and all variables passed the Bartlett sphere test, indicating that factor analysis can be performed. The factor loading of all items is greater than 0.5 , and the cumulative variance explanation rate is high, indicating that the structural validity of the scale meets the requirements. Further calculation of the CR and AVE of each factor meets the corresponding standards, showing that the scale has good convergence validity. The specific results are shown in Table 1 .

\subsection{Descriptive Statistics and Correlation Analysis}

Through the Pearson correlation coefficient test, the mean, standard deviation and correlation coefficient of the main variables are shown in Table 2. The relevant analysis results are consistent with the previous assumptions, indicating that the performance appraisal orientation is different, and the situation of employees' knowledge hiding also changes.

\subsection{Hypothesis Testing}

Public institution was taken as a reference to set the company type as a dummy variable. After that, multiple linear regression was used to test the above hypothesis. The results are shown in Table 3.

The results in Model 1 suggest that developmental PA has a significant negative effect on knowledge hiding ( $\beta=-0.312, p<0.001)$, while evaluative PA has a significant positive effect on knowledge hiding ( $\beta$ $=0.309, \mathrm{p}<0.001$ ), which verified $\mathrm{H} 1$ and $\mathrm{H} 2$. At the same time, developmental PA is positively related to cooperative climate $(\beta=0.509, \quad \mathrm{p}<0.001)$, while evaluative PA is positively related to cooperative climate $(\beta=0.796, p<0.001), \mathrm{H} 3$ and $\mathrm{H} 4$ are supported. In Model 2, cooperative climate and competitive climate were entered. The influence of cooperative climate on knowledge hiding is marginally significant $(\beta=-0.135$, $\mathrm{p}<0.1)$, which shows that cooperative climate plays a part of the mediating role between developmental PA and knowledge hiding. Evaluative PA positively related to knowledge hiding $(\beta=0.173, p<0.05)$, and competitive climate is positively related to knowledge hiding $(\beta=0.159, p<0.05)$, which indicates that competitive climate intermediates the relationship between evaluation PA and knowledge hiding, so $\mathrm{H} 5$ and $\mathrm{H} 6$ are supported. 
Table 2. Descriptive statistics and correlation coefficients

\begin{tabular}{|l|l|l|l|l|l|l|l|}
\hline Variable & Mean & SD & 1 & 2 & 3 & 4 & 5 \\
\hline 1.Developmental PA & 3.637 & 0.817 & 1 & & & & \\
\hline 2.Evaluative PA & 3.670 & 0.714 & 0.055 & 1 & & & \\
\hline 3.Cooperative Climate & 3.873 & 0.684 & $0.641^{* *}$ & -0.061 & 1 & & \\
\hline 4.Competitive Climate & 3.520 & 0.750 & -0.014 & $0.729^{* *}$ & -0.083 & 1 & \\
\hline 5.Knowledge Hiding & 2.149 & 0.668 & $-0.400^{* *}$ & $0.319^{* *}$ & $-0.391^{* *}$ & $0.321^{* *}$ & 1 \\
\hline
\end{tabular}

Note: ${ }^{\star *} p<0.01$.

Table 3. Regression analysis results

\begin{tabular}{|c|c|c|c|c|}
\hline \multirow{2}{*}{ Variables } & \multicolumn{2}{|c|}{ Knowledge hiding } & \multirow{2}{*}{$\begin{array}{c}\text { Cooperative } \\
\text { climate }\end{array}$} & \multirow{2}{*}{$\begin{array}{l}\text { Competitive } \\
\text { climate }\end{array}$} \\
\hline & Model 1 & Model 2 & & \\
\hline Age & -0.128 & -0.127 & -0.022 & -0.025 \\
\hline Gender & -0.012 & -0.028 & -0.117 & 0.001 \\
\hline Education & -0.042 & -0.047 & -0.062 & -0.017 \\
\hline Company 1 & 0.070 & 0.051 & -0.122 & 0.020 \\
\hline Company 2 & 0.162 & 0.151 & -0.085 & 0.023 \\
\hline Company 3 & $0.424^{*}$ & 0.322 & $-0.705^{\star \star \star}$ & 0.046 \\
\hline Rank & -0.018 & -0.015 & -0.021 & -0.040 \\
\hline Work experience & 0.001 & -0.006 & 0.035 & $0.074^{*}$ \\
\hline Developmental PA & $-0.312^{\star * \star}$ & $-0.234^{* \star *}$ & $0.509^{* * *}$ & -0.060 \\
\hline Evaluative PA & $0.309 * * *$ & $0.173^{*}$ & -0.076 & $0.796^{\star * *}$ \\
\hline Cooperative Climate & & $-0.135(p=0.093)$ & & \\
\hline Competitive Climate & & $0.159^{*}$ & & \\
\hline$\Delta R^{2}$ & 0.329 & 0.350 & 0.541 & 0.566 \\
\hline $\mathrm{F}$ & $10.669^{* \star \star}$ & $9.703^{* * *}$ & $25.712^{\star * \star}$ & $28.4147^{\star * \star}$ \\
\hline
\end{tabular}

Note: ${ }^{*} \mathrm{p}<0.05 ; * * \mathrm{p}<0.01 ; * * * \mathrm{p}<0.001$.

\section{CONCLUSION}

First, this paper identified different PA orientations as a new premise for knowledge hiding and clarifies the relationship between PA orientation and knowledge hiding. That is, the developmental PA has a significant negative impact on knowledge hiding, while evaluative PA positively related to knowledge hiding. This conclusion conforms to the social exchange theory and also enriches the research on the factors affecting knowledge hiding.

Secondly, research shows that developmental PA has a positive influence on cooperative climate, and evaluative PA has a positive influence on competitive climate. Therefore, when the organization puts the focus of assessment on employee development, the potential and creativity displayed by employees in the work process are more important, which promotes resource sharing and collaboration at work, thus forming a cooperative climate. On the contrary, when employees' past work performance is quantified and becomes the direct basis for their promotion or dimission, the awareness of good and bad among employees will be stimulated and strengthened, and the competitive climate will be strengthened under constant comparison.

At the same time, we further examined the mediating role of different organizational climate between different PA orientations and knowledge hiding. The two-oriented PA can not only directly affect the knowledge transfer within the organization, cooperative climate and competetive climate also play a very important explanatory role between the PA orientation and knowledge hiding.

\section{IMPLICATIONS}

Through the above analysis, we can believe that developmental PA is better than evaluative PA in knowledge-based enterprises, which can effectively inhibit knowledge hiding behavior and promote the long-term development of the organization. However, 
companies must not only avoid excessive use of certain assessment methods, but also avoid PA becoming mere formalities.

First, organizations should flexibly use PA and attach importance to developmental PA. At present, although evaluative PA can improve work efficiency to a certain extent, as the main body of the labor force in the market gradually transforms into knowledge workers, this appraisal method is difficult to meet the development needs of employees, and it will change from time and psychology. Many aspects such as perception and workload put pressure on employees. Therefore, in the era of knowledge economy, companies should pay attention to the role of developmental PA, pay attention to the professional development of employees and provide relevant training in a targeted manner. Managers should increase communication with employees, give employees performance feedback in a timely manner and help them understand the company's strategy. In this way, employees can have mutually beneficial behaviors for the organization.

Second, the negative effects of the competitive climate are worthy of attention by enterprises. Due to fierce competition in many industries, companies have also formulated strict competition plans within the organization in order to improve their competitiveness. However, excessive advocacy of a competitive climate will not only fail to increase work enthusiasm and select outstanding talents, but will also cause divisions within the team and stimulate more knowledge hiding behaviors. Therefore, we suggest that organization managers should control the intensity of competition, reduce the number of internal evaluations and play a positive role in the competitive climate. On the other hand, companies should try their best to eliminate the competitive psychology between peers, such as implementing salary secrecy to reduce the competitive climate.

\section{ACKNOWLEDGMENTS}

This work was supported by the [Major Program of The National Social Science Fund of China \#1] under Grant [No. 15ZDA022].

\section{REFERENCES}

[1] M. Škerlavaj, C.E. Connelly, M. Černe, A. Dysvik, Tell Me If You Can: Time Pressure, Prosocial Motivation, Perspective Taking, And Knowledge Hiding, J. Knowl. Manag. 22 (2018) 1489-1509.

[2] D.P. Ford, D.S. Staples, What is Knowledge Sharing from the Informer's Perspective, Int. J. Knowl. Manag. 4 (2008) 1-20.

[3] A. Serenko, N. Bontis, Understanding counterproductive knowledge behavior: antecedents and consequences of intraorganizational knowledge hiding, J. Knowl. Manag. 20 (2016) 1199-1224.

[4] W.R. Boswell, J.W. Boudreau, Separating the Developmental and Evaluative Performance Appraisal Uses, J. Bus. Psychol, 16 (2002) 91-412.

[5] P. Wen, L.L. Bao, C. Chen, The Impact of Performance Appraisal Orientation on Knowledge Sharing Behavior: A Study Based on Social Exchange Theory, Manag. Rev. 24 (2012) 127136.

[6] C.E. Connelly, D. Zweig, J. Webster, J.P. Trougakos, Knowledge Hiding in Organizations, J. Organ. Behav. 33 (2012) 64-88

[7] A.S. Tsui, J.L. Pearce, L.W. Porter, A.M. Tripoli, Alternative Approaches to The Employ Organization Relationship: Does Investment in Employees Pay Off, Acad. Manage. J. 40 (1997) 1089-1121.

[8] S.P. Brown, W.L. Cron, J.W. Slocum, Effects of Trait Competitiveness and Perceived Intraorganizational Competition on Salesperson Goal Setting and Performance, J. Marketing. 62 (1998) 88-98.

[9] F.J. Flynn, J.A. Chatman, The Influence of Demographic Heterogeneity on the Emergence and Consequences of Cooperative Norms in Work Teams, Acad. Manage. J. 44 (2001) 956-974.

[10] E.M. Campbell, H. Liao, A. Chuang, J. Zhou, Y. Dong, Hot Shots and Cool Reception: An Expand View of Social Consequences of High Performance at Work, J. Appl. Psychol. 5 (2017) 845-866.

[11] T.D. Fletcher, D.A. Major, D.D. Davis, The Interactive Relationship of Competitive Climate and Trait Competitiveness with Workplace Attitudes, Stress, and Performance, J. Organ. Behav. 29 (2008) 899-922.

[12] G.R. Salancik, J. Pfeffer, A Social Information Processing Approach to Job Attitudes and Task Design, Admin. Sci. Quart. 23 (1978) 224-253.

[13] M. Černe, C.G.L. Nestad, M. Škerlavaj, What goes Around Comes Around: Knowledge Hiding, Perceived Motivational Climate, and Creativity, Acad. Manage. J. 57 (2014) 72-192.

[14] C. Yang, M.F. Tang, Influencing Mechanism of Perceived Competitive Climate on Employees' Knowledge Hiding, Sci. Technol. Prog. Policy, 17 (2018) 131-138.

[15] R. Loi, Y. Mao, H.Y. Ngo, Linking Leader Member Exchange and Employee Work Outcomes: The Mediating Role of Organizational Social and Economic Exchange, Manage. Organ. Rev. 5 (2009) 401-422. 